\title{
Xanthogranuloma in the Suprasellar Region
}

\section{-Case Report-}

\author{
Sei SUGATA, Hirofumi HIRANO, Kazutaka YATSUSHIRO, \\ Shunji YunOUe, Katsumi NAKAMURA*, and Kazunori ARITA \\ Department of Neurosurgery, Graduate School of Medical and Dental Sciences, \\ Kagoshima University, Kagoshima; \\ ${ }^{*}$ Department of Neurosurgery, Fujimoto Hayasuzu Hospital, Miyakonojo, Miyazaki
}

\begin{abstract}
A 26-year-old man presented with a xanthogranuloma located exclusively in the suprasellar region manifesting as general fatigue, bitemporal hemianopsia, and polyuria. Endocrinological examination disclosed severe hypopituitarism. Magnetic resonance imaging demonstrated a clearly defined suprasellar mass that was heterogeneously enhanced after gadolinium administration and was markedly hypointense on $T_{2}$-weighted images. The tumor was subtotally removed under a preoperative diagnosis of craniopharyngioma. Histological examination found fibrous tissue with abundant cholesterol clefts, multinucleated giant cells, and hemosiderin deposits, but no epithelial cells. Xanthogranulomas of the sellar region are reported to be predominantly located in the sella turcica, but should be included in the differential diagnosis even in cases of suprasellar mass lesions.
\end{abstract}

Key words: xanthogranuloma, cholesterol granuloma, suprasellar region, craniopharyngioma

\section{Introduction}

Xanthogranulomas, also known as cholesterol granulomas, are granulomatous lesions characterized by cholesterol clefts, hemosiderin deposits, multinucleated foreign body giant cells, macrophage accumulation, and fibrous proliferation. ${ }^{1-5,7,10)}$ Cholesterol granulomas in the head region are found in the middle ear, petrous apex, paranasal sinuses, and choroid plexus. ${ }^{2,5,6)}$ Xanthogranulomas of the sellar region are very rare and mainly located in the sella turcica. ${ }^{1,3,4,10)}$ Xanthogranulomas without an intrasellar portion are very rare. A considerable number of tumors previously identified as craniopharyngioma may in fact have been xanthogranulomas. ${ }^{3-5}$

We report a case of xanthogranuloma manifesting as bitemporal hemianopsia and hypopituitarism confined to the suprasellar region, which was preoperatively diagnosed as craniopharyngioma.

\section{Case Report}

A 26-year-old man had a 10-year history of general fatigue. He was $172 \mathrm{~cm}$ in height and weighed $65 \mathrm{~kg}$.

Received January 23, 2008; Accepted November 20, 2008
Physical examination revealed complete absence of axillary and pubic hair. Perimetry showed bitemporal hemianopsia with normal visual acuity. $\mathrm{He}$ had polyuria and polydipsia, and his daily urine volume for the last 5 years had been between 3000 and $4000 \mathrm{ml}$.

The anterior pituitary provocation test with thyrotropin-releasing hormone $(500 \mu \mathrm{g})$, luteinizing hormone-releasing hormone (100 $\mu \mathrm{g})$, and regular insulin (6 units) revealed impairment of the secretory functions of growth hormone, cortisol, and gonadotropin (Table 1). His free tri-iodothyronine and free thyroxine levels were also low. Hydrocortisone and desmopressin replacement was started followed by levothyroxine replacement.

Brain computed tomography showed the suprasellar mass as slightly high density. Magnetic resonance (MR) imaging demonstrated a clearly defined mass with a diameter of $30 \mathrm{~mm}$ appearing as mainly isointense, with patchy hypointensity on $\mathrm{T}_{1}$ and remarkable hypointensity on $\mathrm{T}_{2}$-weighted images. The mass was heterogeneously enhanced and no cystic portions were observed. Thin pituitary gland attached to the sellar floor was clearly seen under the mass. There was fluid space with an intense of cerebrospinal fluid between the suprasellar mass and the pituitary gland (Fig. 1). Our preoperative di- 
Table 1 Anterior pituitary provocation test using thyrotropin-releasing hormone, luteinizing hormone (LH)-releasing hormone, and regular insulin

\begin{tabular}{lcccc}
\hline & 0 min & $30 \mathrm{~min}$ & $60 \mathrm{~min}$ & $90 \mathrm{~min}$ \\
\hline BS (mg/dl) & 89 & 56 & 37 & 74 \\
GH $(\mathrm{ng} / \mathrm{ml})$ & $<0.1$ & 0.1 & 0.1 & 0.1 \\
IGF-1 (ng/ml) & 83 & N/A & N/A & N/A \\
Cortisol $(\mu \mathrm{g} / \mathrm{dl})$ & 2.8 & 4.6 & 3.6 & 2.7 \\
ACTH $(\mathrm{pg} / \mathrm{ml})$ & 10.6 & N/A & N/A & N/A \\
TSH $(\mu \mathrm{IU} / \mathrm{ml})$ & 2.44 & 22.05 & 22.26 & 21.99 \\
free T3 $(\mathrm{pg} / \mathrm{ml})$ & 2.5 & N/A & N/A & N/A \\
free T4 $(\mathrm{ng} / \mathrm{dl})$ & 0.52 & N/A & N/A & N/A \\
PRL $(\mathrm{ng} / \mathrm{ml})$ & 16.4 & 34 & 25 & 22.7 \\
LH $(\mathrm{mIU} / \mathrm{ml})$ & $<0.1$ & 0.1 & 0.1 & 0.1 \\
FSH $(\mathrm{mIU} / \mathrm{ml})$ & $<0.3$ & 1.1 & 1.2 & 1.5 \\
Testosterone $(\mathrm{ng} / \mathrm{dl})$ & $<10$ & N/A & N/A & N/A \\
\hline
\end{tabular}

ACTH: adrenocorticotropic hormone, BS: blood sugar, free T3: free tri-iodothyronine, free T4: free thyroxine, FSH: follicle-stimulating hormone, GH: growth hormone, IGF-1: insulin-like growth factor-1, N/A: not assessed, PRL: prolactin, TSH: thyroidstimulating hormone.

agnosis was craniopharyngioma.

Surgical exploration via the interhemispheric approach revealed a well-defined tumor with a yellowish capsule underneath the optic chiasm. The mass was fibrous and hypovascular and was resected piecemeal. Poorly developed diaphragma sellae existed beneath the tumor. And the tumor had no contact with the pituitary gland. The tumor was subtotally removed, and a portion strongly attached to the pituitary stalk was left in situ.

Histological examination showed that the tumor consisted of fibrous tissue with abundant cholesterol clefts surrounded by multinucleated giant cells (Fig. 2). Hemosiderin deposits were also seen. No epithelial cells positive for epithelial membrane antigen or cytokeratin were observed in any part of the tumor including tumor capsule. There was no evidence of calcification.

Postoperatively, his visual field defect improved. However, endocrinological examination showed no improvement in pituitary function at 3 months after the operation. MR imaging showed that the mass had been subtotally removed (Fig. 3). The most recent follow-up MR imaging performed at 12 months postoperatively found no evidence of tumor recurrence.

\section{Discussion}

Xanthogranuloma of the sellar region was first
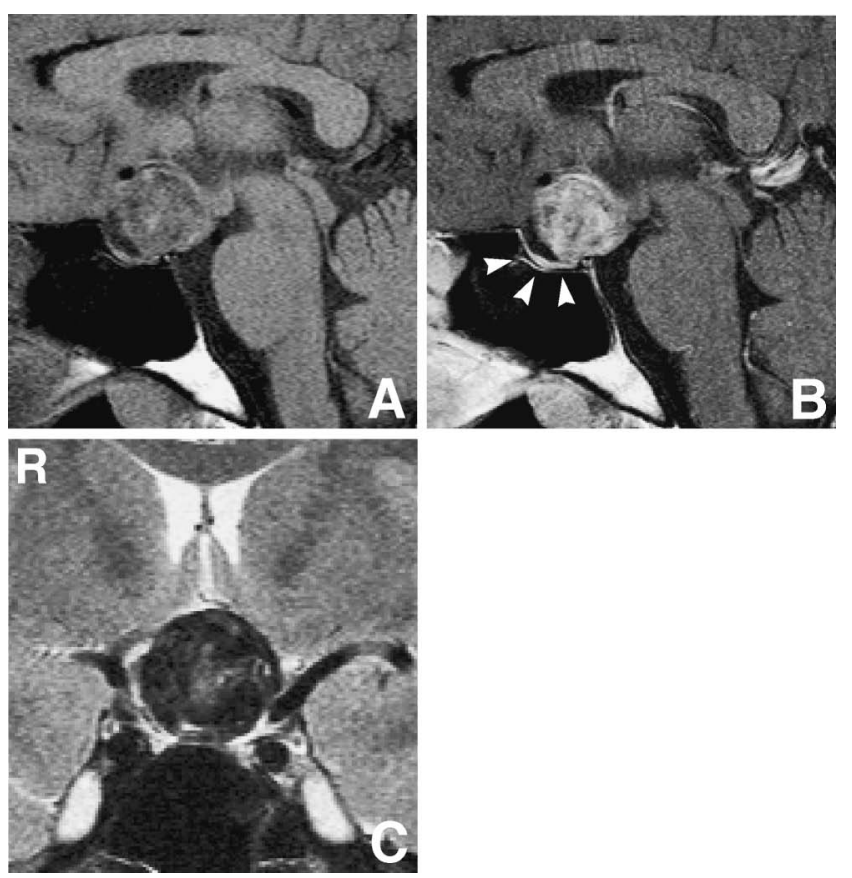

Fig. 1 A, B: Preoperative sagittal $\mathrm{T}_{\mathbf{1}}$-weighted magnetic resonance (MR) images showing a suprasellar round tumor measuring $30 \mathrm{~mm}$ in diameter and compressing the optic chiasma upward (A), and heterogeneous enhancement by contrast medium (B). The thin pituitary gland is located at the bottom of the sella turcica (arrowheads) and is totally separated from the tumor (B). C: Coronal $T_{2}$-weighted MR image showing the tumor as markedly hypointense.

reported in 1988, ${ }^{7)}$ with only 4 of 211 sellar and juxtasellar tumors $(1.9 \%)$ showing the features typical of cholesterol granulomas. Only 2 xanthogranulomas (1.3\%) were encountered among 159 tumors arising in the intra-parasellar region over 5 years. ${ }^{3)}$ Many xanthogranulomas of the sellar region were possibly incorrectly identified as craniopharyngiomas. Among 110 tumors diagnosed as craniopharyngiomas, 37 (33.6\%) predominantly consisted of a xanthogranulomatous component. ${ }^{5}$ Most of these tumors did not manifest the histological features of craniopharyngiomas, and some contained no epithelial component. Compared to classical craniopharyngiomas, xanthogranulomas characteristically occur in adolescent and young adults, predominantly at an intrasellar location, with smaller size and more severe endocrinologic deficiencies, but are more easily resected with good treatment outcomes. Therefore, xanthogranulomas of the sellar region should be differentiated from classical craniopharyngiomas. ${ }^{5}$ 

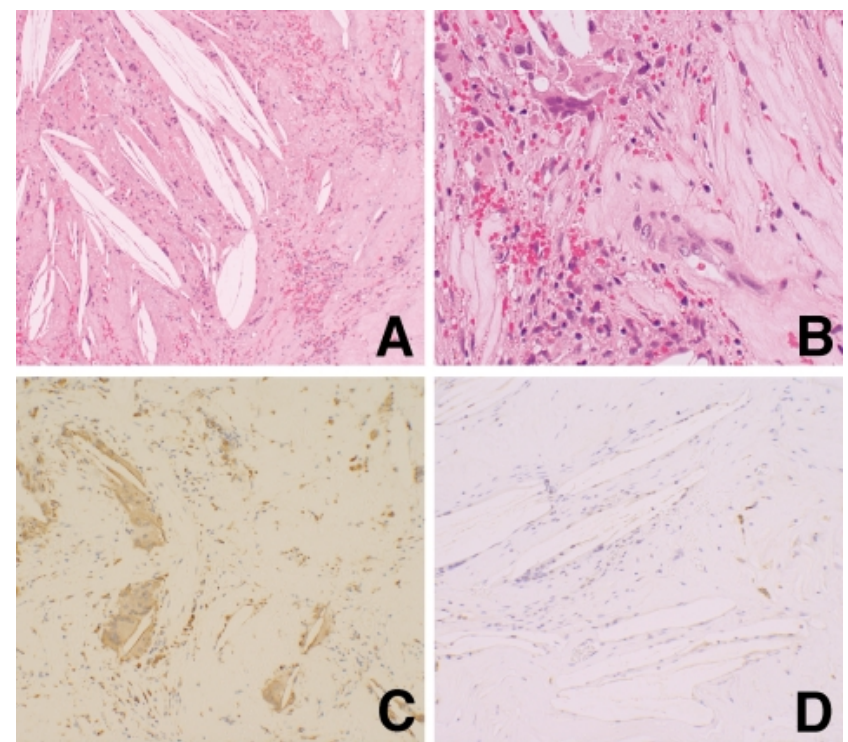

Fig. 2 Photomicrographs of the resected tumor showing the tumor consisted of fibrous tissue intermingled with cholesterol clefts and hemosiderin deposits (A), multinucleated giant cells surrounding the cholesterol clefts (B, C), and no cytokeratin-positive epithelial cells in any part of the tumor (D). A: Hematoxylin and eosin (HE) stain, $\times 200$. B: HE stain, $\times 400$. C: Immunohistochemical stain for KP-1 (monocyte and macrophage marker), $\times 200$. D: Immunohistochemical stain for cytokeratin, $\times 200$.

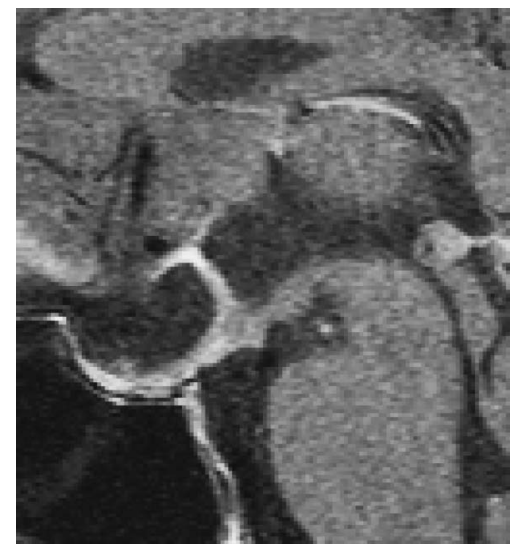

Fig. 3 Postoperative sagittal $T_{1}$-weighted magnetic resonance image with gadolinium revealing subtotal removal of the tumor.

The histogenesis of xanthogranuloma remains unclear. Craniopharyngiomas and Rathke's cleft cysts may induce a severe inflammatory process triggered by leakage of cyst content into the surrounding tumor tissue or by intratumoral hemorrhage ${ }^{5)}$ that may lead to granulomatous degeneration of these tumors. Degenerative changes in pituitary adenomas may act as a trigger, ${ }^{7}$ and extreme adeno- or infundibuloneuro-hypophysitis may result in giant cell granuloma. ${ }^{8)}$ Xanthogranulomas of the sellar region may be a local manifestation of Erdheim-Chester disease, which is associated with multiple organ histiocytosis. ${ }^{9)}$ Severe inflammatory changes leading to granulomatous degeneration may result in serious damage to the hypothalamo-pituitary axis and so comprise the viability of preexisting tumor tissue. This hypothesis may explain the seriousness of the hypopituitarism symptoms, and the good prognosis for patients with this tumor.

Most reported xanthogranulomas of the sellar region were either located in the sella turcica or had an intrasellar portion. ${ }^{1,3-5,10)}$ We postulate that the preferred intrasellar location of xanthogranulomas reflects earlier pathologies of intrasellar origin such as Rathke's cleft cysts, pituitary adenoma, or hypophysitis. However, the tumor in our case was found at a classical location for craniopharyngiomas, i.e. above the pituitary gland and adjacent to the pituitary stalk. Craniopharyngiomas usually arise in the pituitary stalk and grow, at least during the initial stage, mainly in the suprasellar space. Based on these considerations, we speculate that our patient initially had a craniopharyngioma.

One of the distinctive MR imaging features in our case was the marked hypointensity of the lesion on $\mathrm{T}_{2}$-weighted images, which probably reflected the histologically verified hemosiderin deposits in the tumor. Six previous cases of sellar xanthogranuloma with MR imaging findings all manifested hypointensity on $\mathrm{T}_{2}$-weighted MR imaging. No histological evidence of calcification was found in 5 of those 6 cases, but the tumors contained hemosiderin deposits or focal hemorrhages. ${ }^{1,3,4,10)}$ Such micro- or focal hemorrhages may be essential in the formation of xanthogranulomas, as the trigger for granulomatous changes, or as a result of these changes. Hypointensity of the lesion on preoperative $T_{2^{-}}$ weighted images should alert to the possibility that the tumor may be a xanthogranuloma.

Xanthogranuloma should be included in the differential diagnosis of suprasellar tumors. The seriousness of the hypopituitarism, the hypointensity on $\mathrm{T}_{2}$-weighted MR imaging, and the absence of calcification may support the preoperative diagnosis. Histological confirmation of the diagnosis will avoid unnecessary radiation treatment of this benign tumor. 


\section{Acknowledgment}

This study was aided by Health and Labour Sciences Research Grants from the Japanese Ministry of Health, research on intractable diseases, hypothalamo-pituitary dysfunction research group, 2006.

\section{References}

1) Burt MG, Morey AL, Turner JJ, Pell M, Sheehy JP, Ho KK: Xanthomatous pituitary lesions: A report of two cases and review of the literature. Pituitary 6: 161-168, 2003

2) Gherini SG, Brackmann DE, Lo WW, Solti-Bohman LG: Cholesterol granuloma of the petrous apex. Laryngoscope 95: 659-664, 1985

3) Jung CS, Schanzer A, Hattingen E, Plate KH, Seifert V: Xanthogranuloma of the sellar region: Case report. Acta Neurochir (Wien) 148: 473-477, 2006

4) Murao K, Imachi $H$, Ishida $T$, Kushida $Y$, Haba R, Matsumoto Y, Tamiya T: [Panhypopituitarism induced by xanthogranuloma of the sellar region]. Nippon Naika Gakkai Zasshi 94: 2597-2599, 2005 (Jpn)

5) Paulus W, Honegger J, Keyvani K, Fahlbusch R: Xanthogranuloma of the sellar region: A clinicopathological entity different from adamantinomatous craniopharyngioma. Acta Neuropathol (Berl) 97:
377-382, 1997

6) Pear BL: Xanthogranuloma of choroid plexus. AJR Am J Roentgenol 143: 401-402, 1984

7) Shirataki K, Okada S, Matsumoto S: [Histopathological study of the "cholesterol granuloma reaction" in the sellar and juxta-sellar tumors]. No To Shinkei 40: 133-139, 1988 (Jpn, with Eng abstract)

8) Siqueira E, Tsung JS, Al-Kawi MZ, Woodhouse N: Case report: Idiopathic giant cell granuloma of hypophysis: An unusual cause of panhypopituitarism. Surg Neurol 32: 68-71, 1989

9) Thaira O, Bernd WS, Hin SC, Chang MCL, Koh PW: Multiple system Erdheim-Chester disease with massive hypothalamic-sellar involvement and hypopituitarism: Case report and review of the literature. J Neurosurg 96: 344-351, 2002

10) Yonezawa K, Shirataki K, Sakagami Y, Kohmura E: Panhypopituitarism induced by cholesterol granuloma in the sellar region: Case report. Neurol Med Chir (Tokyo) 43: 259-262, 2003

Address reprint requests to: Kazunori Arita, M.D., Department of Neurosurgery, Graduate School of Medical and Dental Sciences, Kagoshima University, 8-35-1 Sakuragaoka, Kagoshima 890-8520, Japan. e-mail:karita@m2.kufm.kagoshima-u.ac.jp 